\title{
The role of the South African Medical Research Council in reducing lead exposure and preventing lead poisoning in South Africa
}

\author{
A Mathee, ${ }^{1-3} \mathrm{PhD} ; \mathrm{N}$ Naicker, ${ }^{2-4} \mathrm{PhD} ;$ Y von Schirnding, ${ }^{5} \mathrm{PhD}$ \\ ${ }^{1}$ Environment and Health Research Unit, South African Medical Research Council, Johannesburg, South Africa \\ ${ }^{2}$ Environmental Health Department, Faculty of Health Sciences, University of Johannesburg, South Africa \\ ${ }^{3}$ School of Public Health, Faculty of Health Sciences, University of the Witwatersrand, Johannesburg, South Africa \\ ${ }^{4}$ National Institute for Occupational Health, National Health Laboratory Service, Johannesburg, South Africa \\ ${ }^{5}$ Mailman School of Public Health, Columbia University, New York, USA
}

Corresponding author: A Mathee (amathee@mrc.ac.za)

Even at low levels in blood, lead has been associated with reduced IQ scores, behavioural problems, learning impediments, aggression and violent behaviour. Since the 1980s, the South African Medical Research Council (SAMRC) has been investigating the sources of exposure to lead in South Africa (SA), the groups at highest risk of lead poisoning and a selection of the myriad associated health and social consequences. SAMRC research evidence contributed to the phasng out of leaded petrol, restrictions on lead in paint and other interventions. Subsequently, childhood blood lead levels in SA declined significantly. More recent studies have revealed elevated risks of lead exposure in subsistence fishing and mining communities, users of arms and ammunition, those ingesting certain traditional medicines, and users of certain ceramicware and artisanal cooking pots. Lead-related cognitive damage costs the SA economy USD17.7 (ZAR261.3) billion annually, justifying further SAMRC investment in lead exposure research in the country.

S Afr Med J 2019;109(11 Suppl 1):S25-S29. https://doi.org/10.7196/SAMJ.2019.v109i11b.14271

Lead is a toxic metal that is abundant in the earth's crust. It has been mined and used for millennia in ancient cultures, and awareness of the toxicity of lead dates back at least 2000 years. ${ }^{[1,2]}$ However, a finer understanding of the depth and scale of the harmful effects of lead has been achieved over the past century in particular, alongside technical innovations (for example, in the measurement of lead concentrations at lower levels in blood) and increasingly sophisticated epidemiological and toxicological studies. It is now known that lead exposure is highest in the youngest and poorest groups in any society ${ }^{[3]}$ and detrimentally affects virtually all human organs and systems. Even at very low concentrations in blood, lead has been associated with reductions in IQ scores, ${ }^{[4]}$ behavioural abnormalities, ${ }^{[5]}$ poor school performance ${ }^{[6]}$ and hearing loss. ${ }^{[7]}$ More recently, lead exposure in early life has been associated with aggressive and violent behaviour during adolescence and early adulthood, ${ }^{[8-10]}$ and at higher concentrations with anaemia, ${ }^{[11]}$ hypertension, ${ }^{[12]}$ cardiac disease ${ }^{[13]}$ and reduced fertility, ${ }^{[14]}$ and, at very high concentrations, with coma and death. ${ }^{[15]}$

Despite its known toxicity, lead continues to be widely used in contemporary society, including in paint, firearms, ammunition, fishing sinkers, traditional medicines, toys, ceramicware, cabling, cosmetics, protective gear, artisanal products such as cookware, and electronic products such as computers and mobile telephones. ${ }^{[16]}$ While there have been incidents of serious, mass-based lead poisoning over the past decade, ${ }^{[15,17]}$ most people are exposed to low levels of lead on a chronic basis. With increasing appreciation of the harmful health effects of lead at low concentrations in blood, countries have responded with a range of protective interventions, including the introduction, or reduction, of blood lead action levels for children. In the USA for example, blood lead action or reference levels have been reduced from $25 \mu \mathrm{g} / \mathrm{dL}$ in the $1980 \mathrm{~s}$, through $10 \mu \mathrm{g} / \mathrm{dL}$, to the current level of $5 \mu \mathrm{g} / \mathrm{dL}{ }^{[18]}$ There is, however, widespread consensus around the absence of a threshold of safety for lead; no matter how low its level in blood, lead is harmful to health. ${ }^{[18]}$

Since the 1980s, the South African Medical Research Council (SAMRC) has invested in a long-term programme of research to characterise lead exposure in South Africa (SA), identify key risk factors and examine the health and social impacts in the population. In this paper, we outline the key findings of SAMRC research on lead exposure, how the research has been translated into protective actions, and the sources of public exposure to lead that remain on the unfinished action agenda to ensure higher levels of protection in SA against lead exposure, especially for the youngest and poorest in the country.

\section{Sources, settings and groups at risk of exposure to lead in $\mathrm{SA}$}

Lead in petrol

One of the first comprehensive epidemiological investigations of lead exposure in SA was undertaken by the SAMRC in Cape Town in the 1980s. ${ }^{[19-21]}$ It was conducted at a time when SA used amongst the highest levels of lead in petrol $(0.836 \mathrm{~g} / \mathrm{L})$ anywhere in the world. ${ }^{[22]}$ Involving the measurement of lead in air, dust, soil and blood samples from 200 first-grade school children, the study showed alarmingly high, and widespread, lead exposure, with $90-100 \%$ of children having blood lead levels $\geq 10 \mu \mathrm{g} / \mathrm{dL}$. Higher levels of lead exposure were found at schools designated during the apartheid era for coloured (mean $18 \mu \mathrm{g} / \mathrm{dL} ; 13 \% \geq 25 \mu \mathrm{g} / \mathrm{dL}$ ) compared with white children (mean $12 \mu \mathrm{g} / \mathrm{dL} ; 0 \% \geq 25 \mu \mathrm{g} / \mathrm{dL}$ ). Lead exposure was significantly elevated near heavily trafficked roads, and homes that were dusty, in disrepair or overcrowded, as well as low parental education and income, were associated with elevated blood lead levels. ${ }^{[21]}$ 
By 2002, 8 years after the end of apartheid and the abolition of segregationist policies, SAMRC studies showed that blood lead distributions continued to vary by suburb. ${ }^{[23]}$ For example, the mean blood lead level in children attending schools in Woodstock equaled $6.9 \mu \mathrm{g} / \mathrm{dL}$, while in the less heavily trafficked suburb of Hout Bay it was $4.8 \mu \mathrm{g} / \mathrm{dL}$. At the level of school, mean blood lead concentrations ranged from $3.3 \mu \mathrm{g} / \mathrm{dL}$ (Hout Bay) to $8.1 \mu \mathrm{g} / \mathrm{dL}$ (Woodstock). Unpublished data from a survey undertaken in 2007 show similarly wide-ranging differences in mean blood lead concentration across schools in Johannesburg, from $3.0 \mu \mathrm{g} / \mathrm{dL}$ at a school in Soweto to $11.8 \mu \mathrm{g} / \mathrm{dL}$ at a school in the inner-city suburb of Bertrams (A Mathee, personal communication). Subsequent studies showed significantly elevated levels of lead in residential garden soil in Bertrams, ${ }^{[2]}$ indicating a possible pathway of exposure to lead among children in that suburb.

Demonstrating the role of housing conditions and socioeconomic status in the distribution of lead exposure, blood lead concentrations in 2002 continued to vary significantly by apartheid-era population groups, with coloured, black African and white children in the study having mean blood lead concentrations of 7.0, 6.0 and $3.5 \mu \mathrm{g} / \mathrm{dL}$, respectively. ${ }^{[23]}$ As petrol lead levels were incrementally reduced over the 1980s and 1990s, culminating in exclusive use of unleaded petrol in SA from 2006, subsequent SAMRC epidemiological studies demonstrated correspondingly lower blood lead levels in first-grade school children across the country. In Johannesburg for example, mean blood lead levels in firstgrade children declined from 11.9 to $8.1 \mu \mathrm{g} / \mathrm{dL}$ between 1995 and 2007, and from
13.2 to $4.6 \mu \mathrm{g} / \mathrm{dL}$ in the rural village of Pella between 1986 and 2007 (Fig. 1). ${ }^{[25]}$

\section{Lead in paint}

The incidental identification in a 2002 Johannesburg blood lead survey of a 7-year-old girl with a blood lead level of $44.4 \mu \mathrm{g} / \mathrm{dL}$ (relative to a sample $(n=383)$ mean of $9.4 \mu \mathrm{g} / \mathrm{dL}$ ), sparked a series of investigations into lead paint hazards in SA. A home visit revealed that the girl had a severe pica habit and was frequently ingesting paint at both home and school. The paint applied to the walls of her home and school had lead concentrations up to $3940 \mu \mathrm{g} / \mathrm{g}$ and $2601 \mu \mathrm{g} / \mathrm{g}$, respectively (relative to the current, internationally accepted guideline level of $90 \mu \mathrm{g} / \mathrm{g}$ ). ${ }^{[26]}$ Subsequent investigations showed that lead paint had been applied to $20 \%$ of dwellings across the City of Johannesburg, ${ }^{[27]}$ that $96 \%$ of children's play parks had playground equipment coated with lead paint, ${ }^{[28]}$ that paint with highly elevated lead concentrations (up to $145000 \mu \mathrm{g} / \mathrm{g}$ ) had been applied to children's toys and educational equipment (including painted wooden building blocks, airplanes, carts and pencil crayons purchased from toy stores, craft shops, stationery stores and flea/craft markets), ${ }^{[29]}$ and that highly elevated lead concentrations (up to $189000 \mu \mathrm{g} / \mathrm{g}$ ) could be found in enamel paint available to the general public at retail stores, usually without any content label or warning of the hazardous contents. ${ }^{[29]}$

\section{Lead poisoning in subsistence fishing communities}

A study of lead exposure in 160 grade 1, 2 and 3 children living in subsistence fishing communities in the remote coastal villages of Elands Bay and Struisbaai revealed blood

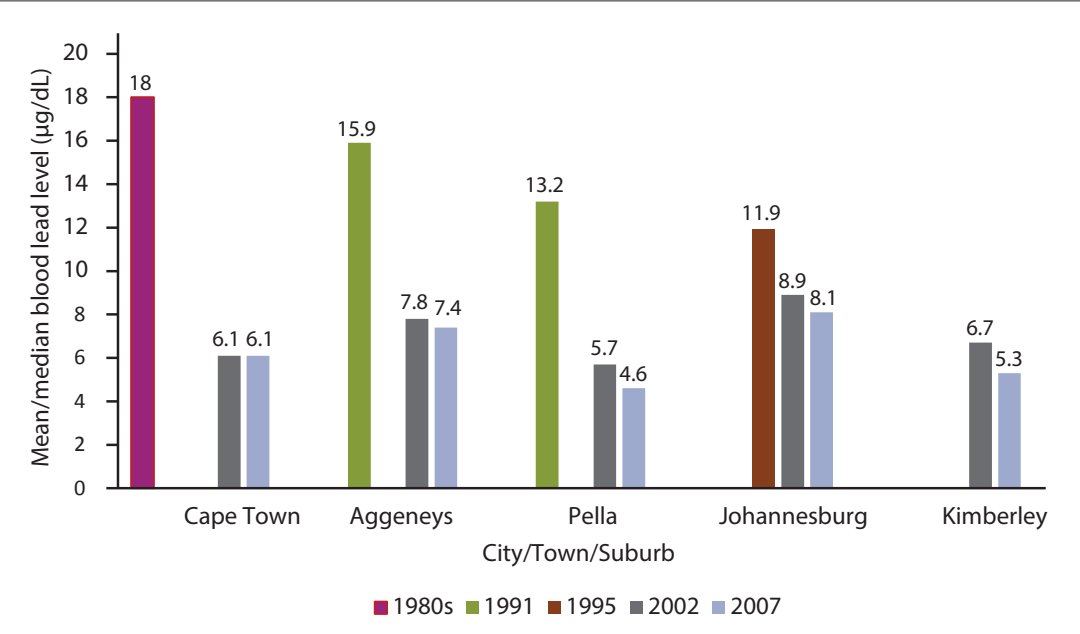

Fig. 1. Mean/median blood lead levels by place and time in South Africa. lead levels ranging from 2.2 to $22.4 \mu \mathrm{g} / \mathrm{dL}$, with the mean level equaling $7.4 \mu \mathrm{g} / \mathrm{dL}$. Around $74 \%$ of children had blood lead levels $\geq 5 \mu \mathrm{g} / \mathrm{dL}$ and $16 \%$ had blood lead levels $\geq 10 \mu \mathrm{g} / \mathrm{dL}^{[30]}$ Questionnaire data showed that in $18 \%$ of dwellings, someone crafted fishing sinkers from molten lead. Two households had a member who had swallowed a lead fishing sinker and only $20 \%$ of respondents were aware that lead was harmful to health. ${ }^{[30]}$

\section{Lead poisoning from Ayurvedic medicines}

Ayurvedic medicines have been gaining in popularity around the world in recent years, but have also been associated with incidents of lead poisoning. In 2012 in Durban, SA, a lead poisoning outbreak among adolescents was associated with the consumption of an Ayurvedic medicine for the treatment of skin conditions. In 2014, 8 individuals (out of 12 affected) were traced and interviewed. Their blood lead levels had initially ranged from 34 to $116 \mu \mathrm{g} / \mathrm{dL}$, and in 2014 from 13 to $34 \mu \mathrm{g} / \mathrm{dL}$. The implicated Ayurvedic capsules had a lead content of $125235 \mu \mathrm{g} / \mathrm{g}$. Participants suffered a wide range of nonspecific ill-health symptoms, and there was a significant delay in the diagnosis of lead poisoning, indicating low levels of awareness of the ongoing risk of lead exposure and poisoning in the general public, as well as the medical fraternity. ${ }^{[31]}$

\section{Childhood exposure to lead in mining communities}

The town of Aggeneys, located in the far north-western part of SA, was developed to support the operation of a lead mine. The SAMRC has undertaken blood lead surveys in Aggeneys, as well as in a control town, Pella, in 1991, 2002 and 2008. Despite higher socioeconomic status (usually a protective factor), blood lead levels in Aggeneys children were significantly elevated relative to their Pella counterparts. The mean blood lead level in Aggeneys was $16 \mu \mathrm{g} / \mathrm{dL}$ compared with $13 \mu \mathrm{g} / \mathrm{dL}$ in Pella (1991). In Aggeneys and Pella, $98 \%$ and $85 \%$ of children had blood lead levels $\geq 10 \mu \mathrm{g} / \mathrm{dL}$, respectively. Blood lead levels were associated with low paternal educational status and paternal personal hygiene practices at the end of workdays. Among children with blood lead levels $>18 \mu \mathrm{g} / \mathrm{dL}, 35 \%$ had failed a year at school, compared with $10 \%$ in children with lower blood lead levels $(p=0.033){ }^{[32]}$

Between 1991 and 2002, the mean blood lead level in Aggeneys children declined significantly, from 15.9 to $7.8 \mu \mathrm{g} / \mathrm{dL}$, but changed little thereafter (by 2008 the mean 
blood lead level was $7.4 \mu \mathrm{g} / \mathrm{dL}$ ). In Pella, on the other hand, there was a statistically significant decline in mean blood lead levels between each study: $13.2 \mu \mathrm{g} / \mathrm{dL}, 5.7 \mu \mathrm{g} / \mathrm{dL}$ and $4.6 \mu \mathrm{g} / \mathrm{dL}$ in 1991, 2002 and 2008, respectively (Fig. 1). It is possible that the declines observed in both Aggeneys and Pella between 1991 and 2002 were due to the introduction of unleaded petrol in 1996. Between 2002 and 2008 the impact of lower levels of lead in petrol may have been overwhelmed by lead exposure associated with lead mining in Aggeneys, compared with Pella. By 2008 more than double the proportion of children in Aggeneys (73\%) relative to Pella (30\%) had blood lead levels $\geq 5 \mu \mathrm{g} / \mathrm{dL}{ }^{[25,32]}$

\section{Exposure to lead prior to birth}

Geophagia is the intentional ingestion of soil and is widely practised in sub-Saharan Africa, especially among pregnant women. While strongly held beliefs about the nutritional benefits of geophagia exist, ingestion of soil has been shown to interfere with the bioavailability of micronutrients (leading to micronutrient deficiencies), and may result in geohelminthic infections, anaemia, hypokalaemia and intestinal obstruction or perforation. ${ }^{[33-35]}$ Geophagic behaviour may also increase exposure to metal contaminants in the soil, including arsenic and lead. ${ }^{[36]}$ During 2010 the SAMRC undertook a crosssectional survey to determine the prevalence of geophagia in pregnant women attending antenatal clinics at the Rahima Moosa Mother and Child Hospital in Johannesburg. Overall, 60/307 women (20\%) reported practicing geophagia during their pregnancy; geophagia was most prevalent in international migrant women (19/60 or $32 \%)$ relative to women born in SA (41/247 or $17 \%)$. Blood lead concentrations were elevated in women who practiced geophagia, but the relationship lost statistical significance after taking account of potential confounding factors. The authors recommended further research on the source and toxic metal content of the soils consumed, as well as the relationship between geophagia and fetal lead exposure in studies with greater statistical power. ${ }^{[37]}$

\section{Lead exposure in users of arms and ammunition}

Following global scrutiny of lead exposure in shooting ranges, ${ }^{[38]}$ the SAMRC conducted a survey of the blood lead levels in users of firearm shooting ranges (one outdoor and three indoor), relative to users of archery ranges in Gauteng Province. A total of 118 (87 shooters and 31 archers) were included in the analysis. Shooters had significantly higher blood lead levels compared with archers, with 36/85 (42.4\%) of shooters v. 2/34 (5.9\%) of archers found to have a blood lead level $\geq 10 \mu \mathrm{g} / \mathrm{dL}(p<0.001)$. At shooting ranges the lowest median blood lead $(7.3 \mu \mathrm{g} / \mathrm{dL})$ was found at the outdoor range, while median blood lead levels at the indoor sites ranged from 9.1 to $16.1 \mu \mathrm{g} / \mathrm{dL}$. Inadequate infrastructure, poor ventilation, poor housekeeping practices, poor personal hygiene practices and low levels of awareness of lead hazards were amongst the risk factors identified. ${ }^{[39]}$

\section{Studies of the health and social effects of lead exposure}

Through a partnership between two SAMRC research units the relationships between blood lead levels at birth and during adolescence, and outcomes such as the age of onset of puberty, behavioural maladjustment, aggression and violence were examined. Data from the Birth to Twenty (Bt20) Cohort, which commenced in 1990, were analysed and included babies born in Soweto, Johannesburg.

\section{Lead exposure and delays in onset of puberty}

The average age of menarche in 712 adolescent females in the Bt20 cohort was 12.7 years, and at 13 years, $4 \%$ and $7 \%$ had reached Tanner stage 5 for pubic hair and breast development, respectively. The mean blood lead level for the sample at 13 years of age was $4.9 \mu \mathrm{g} / \mathrm{dL}$, and $49 \%$ had blood lead levels $\geq 5.0 \mu \mathrm{g} / \mathrm{dL}$. Analyses showed that higher blood lead levels were associated with significant delays in the onset of puberty ${ }^{[40]}$ Earlier, at nine years of age, blood lead levels $\geq 5 \mu \mathrm{g} /$ $\mathrm{dL}$ was associated with slower progression of pubic hair and breast development. In males, elevated blood lead levels at birth were associated with slower tempo of pubic hair development. ${ }^{[41]}$

\section{Lead exposure and the emergence of aggressive and violent behaviour}

Bt20 data were also used to examine the relationships between blood lead levels during adolescence and aggression or violent behaviour. Using 32 items representing rule-breaking and aggressive behavioural characteristics from the Youth Self Report (YSR) it was shown that blood lead levels at 13 years of age were significantly elevated in boys $(6.0 \mu \mathrm{g} / \mathrm{dL})$ relative to girls $(4.5 \mu \mathrm{g} / \mathrm{dL})$, and associated with aggressive behavior (attacking people). ${ }^{[42]}$ By the time the cohort reached 14 years of age, elevated blood lead levels at 13 years were positively associated with direct aggression in males. ${ }^{[43]}$ At the age of $15-16$ years, blood lead levels ranging from 5.0 to $10.0 \mu \mathrm{g} / \mathrm{dL}$ at 13 years of age were associated with physical violence, while blood lead levels $\geq 10 \mu \mathrm{g} / \mathrm{dL}$ were associated physical violence and fighting. Males were more likely than females to be involved in violence using a weapon $(p=0.01)$, physical violence $(p<0.0001)$, and robbing others $(p<0.05) .{ }^{[44]}$

\section{Discussion}

Since the 1980s, the SAMRC has played a singular and fundamental role in revealing who, where and how the SA population has been, or still is, exposed to lead. The earliest studies conducted revealed pervasive contamination of living and learning environments from very high levels of lead added to petrol in SA, especially in urban areas. ${ }^{[19-21,23]}$ Selected results from these studies were included in a submission to the SA Cabinet seeking approval for the phase-out of leaded petrol in the country, which was eventually implemented in 2006, alongside significant reductions in childhood blood lead levels.

A series of SAMRC studies revealed widespread use of lead in paint applied to dwellings, schools, children's playground equipment and toys ${ }^{[27-29]}$ in SA. The evidence generated was successfully used by the SAMRC to lobby for formal regulation of the lead content of paint, rather than rely on the ineffective voluntary industry agreement in place at the time. Such regulations were promulgated in 2009 , and are currently being revised and strengthened by reducing the maximum permissible lead concentration in paint from 600 to 90 parts per million, and extending its applicability from household paints, to all paints, pigments, glazes and other coatings intended for use in commercial and industrial sectors. In this regard the National Department of Health, the Department of Environment, Forestry and Fisheries and the Department of Planning, Monitoring and Evaluation are playing steering roles. The updated lead paint regulations will play a pivotal role in protecting current and future generations against lead hazards at home and school, as well as in painted playground and educational equipment, furniture and toys.

Other measures adopted by various sectors as a result of SAMRC lead and health studies include regular training and awareness programmes at pre-school institutions in Johannesburg and elsewhere, restrictions on the use of lead paint by various provincial and local government departments, investment in lead monitoring equipment at local and provincial tiers of government and joint lead hazard awareness campaigns by the National Department of Health (NDoH), the Department of Agriculture, Forestry and Fisheries, the SA Police Service (SAPS), the National 
Department of Labour (NDoL), the University of Johannesburg and the University of the Witwatersrand.

Notwithstanding the achievements to date, lead exposure remains a high priority environmental and public health concern in SA, with numerous lead sources and potentially vulnerable groups remaining unattended to, for example, communities living around formal sector lead-related industries and sites of e-waste disposal, subsistence fishing communities and users of arms and ammunition. Moving forward, the SAMRC needs to investigate and lobby for protective actions in relevant formal sector activities, including ceramicware and pottery. However, the biggest, and arguably most daunting, lead exposure reduction challenge ahead is the myriad sources of lead in the informal sector, including cottage industries (home-based micro income generation activities). A study of five neighbourhoods in Johannesburg showed that the proportion of households operating at least one cottage industry potentially associated with lead, ranged from 6.7 to $37.1 \%{ }^{[45]}$ The use of lead in cottage industries holds the potential for insidious exposure to high levels of lead amongst all household members, as well as broader contamination of the neighbourhood environment. By way of example, the SAMRC lead research team has recently begun investigation of exposure to aluminium, arsenic and lead from the smelting of waste aluminium (for example, from irons, toasters and vehicle wreckage) to craft cooking pots. ${ }^{[46]}$ Preliminary analyses indicate cause for concern in relation to the leaching of metals into foods prepared in such cookware, and research in this regard is now being scaled up.

\section{Recommendations}

It is our view, and we have lobbied for, to confront the ongoing public health risk of lead exposure in SA through an integrated and sustained programme of action, rather than the current, piecemeal approach. In a cohesive and concerted lead exposure reduction effort, the following would be high-priority actions:

- establishment of an Office of Lead Poisoning Prevention Programme within the $\mathrm{NDoH}$, to coordinate lead exposure and reduction efforts nation-wide

- promulgation of blood lead standards for children and adults

- conducting blood lead screening and surveillance programmes in high-risk settings and groups

- strengthening systems for notification of cases of lead poisoning

- developing standard processes for responding to and documenting cases of lead poisoning

- implementing comprehensive, visible and sustained lead hazard awareness programmes (directed at the general public as well as the health, educational and social development fraternities)

- investing in research to identify and prioritise remaining sources of lead exposure

- implementing measures to eliminate sources of lead in affected areas.

The establishment of inter-sectoral partnerships between the $\mathrm{NDoH}$ and key non-health sectors in the interests of effective prevention of lead exposure and poisoning, would be an important, and costeffective, element of any lead poisoning prevention strategy for SA. Among the actions that may be taken up through inter-sectoral partnerships, would be:

- planning departments could play a powerful, preventive role through preventing the location of new human settlements in close proximity to sources of lead, such as mining or smelting operations and relevant industries or infrastructure

- working with the NDoL to introduce more protective lead screening and interventions for workers, including the reduction of blood lead action levels for workers to levels in closer alignment with international trends

- assisting the SAPS and the Department of Defence, as well as other users of firearms and ammunition, to increase the robustness of blood lead surveillance and protections in these groups

- working with the trade and industry sector to investigate the emerging risks of lead exposure from e-waste

- working with the Department of Small Business Development, local government and other stakeholders, to assess risks of lead exposure from the operation of cottage industries, including subsistence fishing and artisanal pot making, and develop appropriate exposure reduction measures.

The cost of lead exposure reduction efforts may be high, but the cost of inaction is higher. Studies by the SAMRC Burden of Disease Unit conservatively estimated that cardiovascular mortality and disability-adjusted life years (DALYs) in adults aged 30 years and older, as well as mild mental disability (DALYs) in children under 5 years of age from lead exposure, were associated with 1428 (0.3\%) of all deaths in SA in 2000. ${ }^{[47]}$ From a study undertaken by Attina and Trasande ${ }^{[48]}$ (2013) to determine the cost of lead exposure in developing countries, it emerged that Africa is one of the regions in which the public health and social costs of lead exposure are particularly high. SA was determined to be second only to Egypt in bearing an exceptionally high economic burden from the loss of IQ points associated with environmental lead exposure. Annually, the SA economy is conservatively estimated to lose around USD17.7 (ZAR262) billion from lead-related loss of IQ points in children. The analyses did not take account of losses associated with leadrelated ill-health outcomes such as cardiac disease and violent or criminal behaviour. ${ }^{[48]}$ Health economics studies undertaken in the USA show that investments in lead exposure prevention are cost-efficient, yielding public health and societal benefits that significantly outweigh the costs. For each dollar invested in lead paint hazard control, for example, a return of USD17 - USD221 (ZAR251 - ZAR3 262) was yielded, which significantly exceeds the return of between USD5.30 (ZAR78) and USD16.50 (ZAR244) from every dollar spent on immunisations. ${ }^{[49]}$

Lead poisoning has been described as a 'silent poison' with clinical health effects such as reductions in IQ scores, hearing loss, anaemia and increases in violence and aggression not being readily discernible; a blood lead test is usually required to detect lead poisoning. Through the ongoing SAMRC research programme on lead poisoning, a compelling body of evidence of lead exposure and harms has been generated. The essential next step is the translation of the research generated into a concerted and integrated lead exposure reduction programme in SA. The most vulnerable groups - young children and the poor - will be the chief beneficiaries, with benefits for communities and the national economy reaped through improved learning ability and advanced educational achievement, lowered violence (two major socio-political challenges in SA), and other economic benefits. Action to prevent lead exposure makes national health, social, educational and economic sense; inaction is indefensible.

\section{Acknowledgements. None.}

Author contributions. All authors participated in the design, conduct, analysis and reporting of some or most of the studies described. AM drafted the paper, with input from NN and YvS.

Funding. Over the 30-year span of this review, the SAMRC was the predominant funder of the range of studies undertaken and described.

Conflicts of interest. None. 
1. Boeckx RL. Lead poisoning in children. Anal Chem 1986;58(2):274A-288A. https://doi.org/10.1021/ ac00293a001

2. Needlemen HL. History of lead poisoning in the world. International Conference on Lead Poisoning Prevention and Treatment, Bangalore, India: 1999. https://www.biologicaldiversity.org/campaigns/ get_the_lead_out/pdfs/health/Needleman_1999.pdf (accessed 4 November 2019).

3. Tong S, von Schirnding YE, Prapamontol T. Environmental lead exposure: A public health problem of global dimensions. Bull World Health Organ 2000;78(9):1068-1077.
glo

global dimensions. Bull World Health Organ 2000;78(9):1068-1077. Schwartz J. Low-level lead exposure and children's IQ: A meta-ana
Environ Res 1994;65(1):42-55. https://doi.org/10.1006/enrs.1994.1020

5. Chen A, Cai B, Dietrich KN, Radcliffe J, Rogan WJ. Lead exposure, IQ, and behavior in urban 5 - 7-year5. Chen A, Cai B, Dietrich KN, Radcliffe J, Rogan WJ. Lead exposure, IQ, and behavior in urban $5-7$-year-
olds: Does lead affect behavior only by lowering IQ? Pediatrics 2007;119(3):e650. https://doi.org/10.1542/ olds: Does lead a

6. Chandramouli K, Steer CD, Ellis M, Emond AM. Effects of early childhood lead exposure on academic erformance and behavior of school age children. Arch Dis Child 2009;94(11):844-848. https://doi. rg/10.1136/adc.2008.14995

. Schwartz J, Otto D. Lead and minor hearing impairment. Arch Environ Health 1991;46(5):300-305. https://doi.org/10.1080/00039896.1991.9934391 8. Nevin R. Understanding international crime trends: The legacy of preschool lead exposure. Environ Res
2007;104(3):315-336. https://doi.org/10.1016/j.envres.2007.02.008

9. Reyes JW. Lead exposure and behavior: Effects on antisocial and risky behavior among children and adolescents. Economic Inquiry 2015;53(3):1580-1605. https://doi.org/10.1111/ecin.12202

10. Boutwell BB, Nelson EJ, Emo B, et al. The intersection of aggregate-level lead exposure and crime. Environ Res 2016;148:70-85. https://doi.org/10.1016/j.envres.2016.03.023

11. Flora G, Gupta D, Tiwari A. Toxicity of lead: A review with recent updates. Interdiscip Toxicol 2012;5(2):47-58. https://doi.org/10.2478/v10102-012-0009-2

12. Navas-Acien A, Guallar E, Silbergeld EK, Rothenberg SJ. Lead exposure and cardiovascular disease - a systematic review. Environ Health Perspectives 2006;115(3):472-482. https://doi.org/10.1289/ehp.9785

13. Lanphear BP, Rauch S, Auinger P, Allen RW, Hornung RW. Low-level lead exposure and mortality in US adults: A population-based cohort study. Lancet Public Health 2018;3(4):el77-e184. https://doi. org/10.1016/S2468-2667(18)30025-2

14. Sallmén M, Lindbohm M-L, Nurminen M. Paternal exposure to lead and infertility. Epidemiology 2000;11(2):148-152. https://doi.org/10.1097/00001648-200003000-00011

15. Haefliger $\mathrm{P}$, Mathieu-Nold M, Lociciro S, et al. Mass lead intoxication from informal used lead-acid battery recycling in Dakar, Senegal. Environ Health Perspect 2009;117(10):1535-1540. https://doi. org/10.1289/ehp.0900696

16. Mathee A, von Schirnding Y, Montgomery M, Röllin H. Lead poisoning in South African children: The hazard is at home. Rev Environ Health 2004;19(3-4):347-361.

17. Lo Y-C, Dooyema CA, Neri A, et al. Childhood lead poisoning associated with gold ore processing: A village-level investigation - Zamfara State, Nigeria, October - November 2010. Environ Health Perspect 2012;120(10):1450-1455. https://doi.org/10.1289/ehp.1104793

18. Betts KS. CDC updates guidelines for children's lead exposure. Environ Health Perspect 2012;120(7):a268. https://doi.org/10.1289/ehp.120-a268

19. von Schirnding Y, Bradshaw D, Fuggle R, Stokol M. Blood lead levels in South African inner-city children. Environ Health Perspect 1991;94:125-130. https:///doi.org/10.1289/ehp.94-1567937

20. von Schirnding YER, Fuggle RF. A study of the distribution of urban environmental lead levels in Cape Town, South Africa. Sci Total Environ 1996;188(1):1-8. https://doi.org/10.1016/0048-9697(96)05122-4

1. Von Schirnding YER, Fuggle R, Bradshaw D. Factors associated with elevated blood lead levels in innerVon Schirnding YER, Fuggle R, Bradshaw D. Factors asso
city Cape Town children. S Afr Med J 1991;79(4):454-456

city Cape Town children. S Afr Med J 1991;79(4):454-456.
22. Thomas VM, Socolow RH, Fanelli JJ, Spiro TG. Effects of reducing lead in gasoline: An analysis of the Thomas VM, Socolow RH, Fanelli JJ, Spiro TG. Effects of reducing lead in gasoline: An analysis of the
international experience. Environ Sci Technol 1999;33(22):3942-3948. https://doi.org/10.1021/es 990231 international experience. Environ Sci Technol 1999;33(22):3942-3948. https://doi.org/10.1021/es990231
23. Mathee A, Röllin H, von Schirnding Y, Levin J, Naik I. Reductions in blood lead levels among school children following the introduction of unleaded petrol in South Africa. Environ Res 2006;100(3):319children following the introduction of unleaded
322. https://doi.org/10.1016/j.envres.2005.08.001

24. Mathee A, Kootbodien T, Kapwata T, Naicker N. Concentrations of arsenic and lead in residential garden Mathee A, Kootbodien T, Kar weighbourhoods. Environ Res 2018;167:524-527. https://doi.org/10.1016/
soil from four Johannesburg neid envres. 2018.08 .012

25. Naicker N, Mathee A. Trends in lead exposure in a rural mining town in South Africa, 1991-2008. S Afr Med J 2015;105(7):515. https://doi.org/10.7196/samjnew.7809

26. Mathee A, Röllin H, Ditlopo N, Theodorou P. Childhood lead exposure in South Africa. S Afr Med J 2003;93(11):313

27. Montgomery M, Mathee A. A preliminary study of residential paint lead concentrations in Johannesburg. Environ Res 2005;98(3):279-283. https://doi.org/10.1016/j.envres.2004.10.006
28. Mathee A, Singh E, Mogotsi M, et al. Lead-based paint on playground equipment in public children's parks in Johannesburg. Tshwane and Ekurhuleni. S Afr Med J 2009;99(11):819-821.

29. Mathee A, Röllin H, Levin J, Naik I. Lead in paint: Three decades later and still a hazard for African children? Environ Health Perspect 2006;115(3):321-322. https://doi.org/10.1289/ehp.9575

30. Mathee A, Khan T, Naicker N, Kootbodien T, Naidoo S, Becker P. Lead exposure in young schoo children in South African subsistence fishing communities. Environ Res 2013;126:179-183. https:// doi.org/10.1016/j.envres.2013.05.009

31. Mathee A, Naicker N, Teare J. Retrospective investigation of a lead poisoning outbreak from the consumption of an Ayurvedic medicine: Durban, South Africa. Int J Environ Res Public Health 2015;12(7):7804-7813. https://doi.org/10.3390/ijerph120707804

32. von Schirnding Y, Mathee A, Kibel M, Robertson P, Strauss, Blignaut R. A study of pediatric blood lead levels in a lead mining area in South Africa. Environ Res 2003;93(3):259263. https://doi. org/10.1016/S0013-9351(03)00117-8

33. Njiru H, Elchalal U, Paltiel O. Geophagy during pregnancy in Africa: A literature review. Obstet Gynecol Surv 2011;66(7):452-459. https://doi.org/10.1097/OGX.0b013e318232a034

34. Simpson E, Mull JD, Longley E, et al. Pica during pregnancy in low-income women born in Mexico. West J Med 2000;173(1):20-24. https://doi.org/10.1136/ewjm.173.1.20

35. Saathoff E, Olsen A, Kvalsvig JD, et al. Geophagy and its association with geohelminth infection in rural schoolchildren from northern KwaZulu-Natal, South Africa. Trans R Soc Trop Med Hyg 2002;96(5):485-490. http://dx.doi.org/10.1016/S0035-9203(02)90413-X

36. Al-Rmalli SW, Jenkins RO, Watts MJ, et al. Risk of human exposure to arsenic and other toxic elements from geophagy: Trace element analysis of baked clay using inductively coupled plasma mass spectrometry. Environ Health 2010;9(1):79. https:// doi.org/10.1186/1476-069X-9-79

37. Mathee A, Naicker N, Kootbodien T, et al. A cross-sectional analytical study of geophagia practices and blood metal concentrations in pregnant women in Johannesburg, South Africa. S Afr Med J 2014;104(8):568-573. https://doi.org/10.7196/SAMJ.7466

38. Laidlaw MA, Filippelli G, Mielke $\mathrm{H}$, Gulson B, Ball AS. Lead exposure at firing ranges - a review. Environ Health 2017;16(1):34. https://doi.org/10.1186/s12940-017-0246-0

39. Mathee A, de Jager P, Naidoo S, Naicker N. Exposure to lead in South African shooting ranges. Environ Res 2017;153:93-98. https://doi.org/10.1016/j.envres.2016.11.02

40. Naicker N, Norris SA, Mathee A, Becker P, Richter L. Lead exposure is associated with a delay in the onset of puberty in South African adolescent females: Findings from the Birth to Twenty cohort. Sc Total Environ 2010;408(21):4949-4954. https://doi.org/10.1016/j.scitotenv.2010.07.037

41. Nkomo P, Richter LM, Kagura J, Mathee A, Naicker N, Norris SA. Environmental lead exposure and pubertal trajectory classes in South African adolescent males and females. Sci Total Environ 2018;628:1437-1445. https://doi.org/10.1016/j.scitotenv.2018.02.150

42. Naicker N, Richter L, Mathee A, Becker P, Norris SA. Environmental lead exposure and sociobehavioural adjustment in the early teens: The Birth to Twenty cohort. Sci Total Environ 2012;414:120-125. https://doi.org/10.1016/j.scitotenv.2011.11.013

43. Nkomo P, Naicker N, Mathee A, Galpin J, Richter LM, Norris SA. The association between environmental lead exposure with aggressive behavior, and dimensionality of direct and indirect aggression during mid-adolescence: Birth to Twenty Plus cohort. Sci Total Environ 2018:612:472479. https://doi.org/10.1016/j.scitotenv.2017.08.138

44. Nkomo P, Mathee A, Naicker N, Galpin J, Richter LM, Norris SA. The association between elevated blood lead levels and violent behavior during late adolescence: The South African Birth to Twenty Plus cohort. Environ Int 2017;109:136-145. https://doi.org/10.1016/j.envint.2017.09.004

45. Teare J, Kootbodien T, Nacker N, Mathee A. The extent, nature and environmental healt implications of cottage industries in Johannesburg, South Africa. Int J Environ Res and Public Health 2015;12(2):1894-1901. https://doi.org/10.3390/ijerph120201894

46. Weidenhamer JD, Fitzpatrick MP, Biro AM, et al. Metal exposures from aluminum cookware: An unrecognisad public health risk in developing countries. Sci Total Environ 2017;579:805-813. https://doi.org/10.1016/j.scitotenv.2016.11.023

47. Norman R, Mathee A, Barnes B, van der Merwe L, Bradshaw D. Estimating the burden of disease attributable to lead exposure in South Africa in 2000. S Afr Med J 2007;97(8):773-780.

48. Attina TM, Trasande L. Economic costs of childhood lead exposure in low-and middle-income countries. Environ Health Perspect 2013;121(9):1097-1102. https://doi.org/10.1289/ehp.1206424

49. Gould E. Childhood lead poisoning: Conservative estimates of the social and economic benefits of lead hazard control. Environ Health Perspect 2009;117(7):1162-1167. https://doi.org/10.1289 ehp. 0800408 